\title{
Sedentary behavior, physical activity and body composition in adults
}

\author{
(1D) Gerson Luis de Moraes Ferrari 1,2 \\ (iD) Eduardo Rossato de Victo ${ }^{2}$ \\ (iD) Irina Kovalskys ${ }^{3}$ \\ (iD) Aline Veroneze de Mello ${ }^{4}$ \\ (iD)Agatha Nogueira Previdelli ${ }^{5}$ \\ (iD) Dirceu Solé2 \\ (iD) Mauro Fisberg ${ }^{6}$
}

1. Laboratorio de Ciencias de la Actividad Física, el Deporte y la Salud, Facultad de Ciencias Médicas, Universidad de Santiago de Chile, USACH, Santiago, Chile. 2. Disciplina de Alergia, Imunologia Clínica e Reumatologia do Departamento de Pediatria da Universidade Federal de São Paulo (Unifesp), São Paulo, SP, Brasil.

3. Commitee of Nutrition and Wellbeing, International Life Science Institute, Buenos Aires, Argentina. 4. Departamento de Nutrição, Faculdade de Saúde Pública, Universidade de São Paulo, São Paulo, SP, Brasil. 5. Faculdade de Ciências Biológicas e da Saúde, Universidade São Judas Tadeu, São Paulo, SP, Brasil. 6. Instituto Pensi, Fundação Jose Luiz Egydio Setubal, Hospital Infantil Sabará, São Paulo, SP, Brasil.

http://dx.doi.org/10.1590/1806-9282.66.3.314

\section{SUMMARY}

OBJECTIVE: We investigated the associations between objectively assessed sedentary behavior (SB) and moderate-to-vigorous physical activity (MVPA) and body composition variables among a representative sample of Brazilian adults.

METHODS: Using an accelerometer, SB and MVPA were monitored for at least 5 days in 524 participants (261 men; age, 18-65 years). Each minute epoch was classified as sedentary or spent in light, moderate, or vigorous physical activity (LPA, MPA, and VPA, respectively). The measured body composition variables included abdominal perimeter (AP) and neck circumference (NC).

RESULTS: Men accumulated significantly more min/day of MPA (37.82 versus 27.28), VPA (1.10 versus 0.37), MVPA (39.02 versus 27.61), and steps/day $(14,978$ versus 13,443$)$ than women $(p<.001)$. In men, MPA, VPA, MVPA, and steps/day were negatively associated with AP $(p<.05)$ independently of SB. Only VPA was significantly associated with NC $(\beta=0.113 ; p=.002)$. In women, only SB was significantly associated with AP ( $\beta=0.003 ; p=.037)$. There were no significant associations between physical activity intensities and body composition in women.

CONCLUSIONS: Our findings on the unequal association of physical activity with body composition variables between sexes can help inform future intervention strategies in Brasil.

KEYWORDS: Accelerometry. Obesity. Anthropometry.

\section{INTRODUCTION}

Physical activity (PA), a pillar in the prevention and treatment of obesity and cardiovascular diseases (CVD), is inversely associated with excess weight ${ }^{1}$. Whereas a high level of sedentary behavior (SB) probably favors obesity ${ }^{2}$. In general, 50.1\% of Brazilian men and $48 \%$ of women have excess weight, and $12.4 \%$ and $16.9 \%$, respectively, are obese ${ }^{3}$. In addition, only $60.2 \%$ of men and $51.5 \%$ of the women follow the recommendations of moderate to vigorous physical activity (MVPA) $)^{4.5}$. Although population studies have 
revealed that the association between PA and obesity varies according to sex, the relationships between the intensities of PA and health outcomes have not been sufficiently studied. The understanding of these associations is important for the development of public policies and interventions aimed at behavioral changes.

Objective measures of time spent in SB, in different intensities of PA, and the number of steps/day may help to understand the human movement behavior related to obesity. Objective evaluations using accelerometers are commonly included in studies from high-income countries ${ }^{6}$. In contrast, relatively few studies have applied this technology to research in low- and middle-income countries, such as Brasil ${ }^{6}$. The present study investigated the association between SB and MVPA, both objectively assessed, with body composition variables in Brazilian adults according to the intensity of the PA.

\section{METHODS}

\section{Brazilian Study on Nutrition and Health}

The present study was part of the Latin American study on Nutrition and Health (Estudio Latinoamericano de Nutrición y Salud, Elans) ${ }^{7}$, conducted in eight countries of Latin America: Argentina, Brasil, Chile, Colombia, Costa Rica, Ecuador, Peru, and Venezuela. The study included data of the Brazilian Study on Nutrition and Health (Ebans) $)^{8}$. The Ebans is a cross-sectional, populational, household-based survey. The participants were stratified by geographic location (urban areas only), sex, age, and socioeconomic level (SEL). The data were collected between November 2014 and August 2015. The sample included subjects of both genders, aged between 15 and 65 years, who belonged to various regions and cities ${ }^{8}$. All participants signed the Informed Consent Form, and the comprehensive Elans protocol (60953716.4.0000.5505) was approved by the Federal University of São Paulo, Brasil.

\section{Participants}

In total, 1,436 people who participated in the Ebans did not use an accelerometer or had less than five days of valid data, yielding a final sample of 524 participants. In general, we found no significant differences between the participants who did not use accelerometers and those who had valid data in groups stratified by sex $(p=0.644)$, level of formal education $(p=0.110)$, and body mass index (BMI) $(\mathrm{p}=0.813)$.
We excluded from the study: pregnant women and infants, individuals with major physical or cognitive disabilities, which could affect food intake and physical activity, individuals aged $<18$ or $>65$ years, who lived in any residential environment that was not a household, and those unable to read.

\section{Accelerometer}

To monitor SB and MVPA objectively, participants were asked to wear a triaxial accelerometer (model GT3X +, ActiGraph, Pensacola) on an elastic band at hip-height, on the right midaxillary line, for seven days. In addition, they were was asked to put on the device as soon as they woke up and removed it when sleeping, bathing, or swimming. Verbal and written instructions on how to use the accelerometer were provided. Participants completed a diary indicating the start and end time of use of the device and were encouraged to wear it for 12 hours/day, including on both weekend days. Data from at least five days (including at least one weekend day) from the use of the accelerometer were considered acceptable, with at least 10 hours/day of use after excluding sleep time ${ }^{9.10}$. After removing the nocturnal sleep period, the time of non-use was defined as any period of at least 60 consecutive minutes in a zero-count activity.

On the eighth day of data collection, the research team visited the homes of participants to collect the accelerometers. Data were compiled using the latest version of ActiLife (version 6.0; ActiGraph), collected at a sampling rate of $30 \mathrm{~Hz}$, and downloaded in periods of 60 seconds ${ }^{11}$.

Based on the time accumulated, SB was defined as $\leq 100$ counts/min, mild PA (MIPA) as $\geq 101-1951$ counts/ min, moderate PA (MOPA) as $\geq 1,952-5,724$ counts/min, vigorous $\mathrm{PA}$ (VPA) as $\geq 5,725$ counts/min, and MVPA as $\geq 1,952$ counts $/ \mathrm{min}^{12}$. The participants were classified as having fulfilled or not the recommendations of MVPA ${ }^{5}$.

\section{Body Composition}

Bodyweight was measured with a precision of $0.1 \mathrm{~kg}$ using a portable scale (Seca ${ }^{\circledR}$, Hamburg, Germany) up to $200 \mathrm{~kg}$ after removing all heavy clothing items, items in pockets, and shoes ${ }^{13}$. Two measurements were obtained, and the mean was calculated for analysis.

The body height was measured using a portable stadiometer (Seca $213^{\circledR}$, Hamburg, Germany) with a measuring range of 0 to $205 \mathrm{~cm}$. After assembling the 
stadiometer, the subject's height was measured without shoes on $^{13}$. The subject was positioned under the stadiometer, standing in an upright position with their backs against the wall and their heads positioned on the Frankfurt plane ${ }^{13}$. The measurement, taken while inhaling, was repeated, and the average was used for analysis. The BMI $\left(\mathrm{kg} / \mathrm{m}^{2}\right)$ was calculated based on reference data for adults ${ }^{14.15}$.

The abdominal perimeter (AC) was measured to the nearest centimeter, between the last rib and the iliac crest after exhaling, with participants standing up, in accordance with the recommendations by the World Health Organization (WHO) ${ }^{15.16}$. The measurement was taken on exposed skin with non-elastic tape after removing accessories such as belts and girdles in the abdominal region. Each individual stood with their feet together, and arms relaxed on the side of their bodies. The AC $(\mathrm{kg} / \mathrm{m} 2)$ was classified based on reference data for adults ${ }^{17}$.

The NC has recently been used to identify obesity and is correlated with age, weight, and BMI in both sexes $^{18}$. The NC $(\mathrm{cm})$ was measured using a non-elastic tape placed right below the larynx, perpendicular to the long axis of the neck, with the tape, on the front and back of the neck, at the same height ${ }^{19}$. The adults were categorized as $\mathrm{NC}>39 \mathrm{~cm}$ for men and $\mathrm{NC}>5 \mathrm{~cm}$ for women ${ }^{20}$. Each measurement was taken twice to ensure accuracy, and the average was used for the analyses.

\section{Sociodemographic variables}

A questionnaire was used to collect demographic information such as age, gender, years of education, race, and marital status. The SEL was also assessed using a questionnaire whose format was based on the national indices used in Brasil' ${ }^{7}$. The SEL data were divided into three strata (high, medium, and low).

\section{Statistical analysis}

Descriptive statistics included averages, standard deviations, and frequencies, as appropriate. The Kolmogorov-Smirnov tests were applied to evaluate data distributions. To check for differences between sexes, we used the t-test for independent samples and the chi-square test. The Pearson correlation test was used to evaluate the association between SB, different intensities of PA, steps/day, and body composition variables.

Multiple linear regression models were used to examine the independent associations between SB, $\mathrm{PA}$, steps/day, and body composition variables. Our first model was adjusted by region (to allow the grouping of the regional level), age, race, educational level, marital status, and employment situation. The second model was added to the MVPA as an adjustment. When considering PA as a dependent variable, we also made adjustments for SB. The calculations were done using SPSS, version 20.0, with a level of significance of $p<0.05$.

\section{RESULTS}

There were significant differences between men and women regarding race, marital status, and employment situation, but not in age and educational level. Men used the accelerometer for significantly more time than women; however, there was no significant difference in the number of valid days of monitoring between the sexes. There were no significant differences between the sexes regarding SB and MIPA. Men accumulated significantly more minutes of MOPA (10.5 min/day), VPA (0.8 min/day), MVPA (11.4 $\mathrm{min} /$ day), and steps (1,535 steps/day) than women. In general, $60.9 \%$ of the participants met the guidelines for MVPA (Table 1).

There were significant differences between men and women in body weight and height, BMI $\left(\mathrm{kg} / \mathrm{m}^{2}\right)$, $\mathrm{AC}$ (categorical), and NC (cm); however, there were no significant differences in the classification of the BMI, AC (cm), or NC (categorical) between them (Table 1).

Tables 2 and 3 show the results of the multiple linear regression analysis describing the independent association between variables from the accelerometer with body composition (AC and NC) according to sex. There were no significant associations of the SB and MIPA with the AC in men. MOPA, VPA, MVPA, and steps/day were significantly negatively associated with the AC. In women, only SB was significantly associated with the AC, regardless of region, age, race, educational level, marital status, employment situation, and MVPA. On the other hand, MIPA, MOPA, VPA, MVPA, and steps/day were not associated with the AC (Table 2).

In men, there were no significant associations between SB, MIPA, MOPA, MVPA, and steps/day with the NC. Only VPA was negatively associated with the $\mathrm{NC}$, regardless of region, age, race, educational level, marital status, employment situation, and MVPA. In women, there were no significant associations between any variables from the accelerometer and the NC (Table 3). 


\section{DISCUSSION}

This study investigated the association between SB and PA, both objectively assessed, with body composition variables in Brazilian adults. In men, VPA proved to have the greatest potential to influence body composition (mainly regarding AC) than MPA, even after adjusting for SB. In contrast, we found no significant association between SB and body composition variables. In women, only SB was significantly associated with the AC.

TABLE 1. DESCRIPTIVE ANALYSIS (MEAN AND STANDARD DEVIATION, OR FREQUENCY AND PERCENTAGE) OF THE VARIABLES FROM THE ACCELEROMETER AND BODY COMPOSITION IN BRAZILIAN ADULTS

\begin{tabular}{|c|c|c|c|}
\hline Variables & $\begin{array}{l}\text { Men } \\
(n=231)\end{array}$ & $\begin{array}{l}\text { Women } \\
(n=293)\end{array}$ & p-value* \\
\hline Age (years) & $38.44(13.08)$ & $39.68(13.44)$ & 0.269 \\
\hline \multicolumn{4}{|l|}{ Ethnicity } \\
\hline White & $87(38.8)$ & $125(44.6)$ & \multirow{4}{*}{0.014} \\
\hline Black & $47(21.0)$ & $56(20.0)$ & \\
\hline Mixed & $37(16.5)$ & $59(21.1)$ & \\
\hline Others & $60(23.7)$ & $53(14.3)$ & \\
\hline \multicolumn{4}{|l|}{ Educational level } \\
\hline Basic/Primary Education & $96(41.6)$ & $122(41.6)$ & \multirow{3}{*}{0.683} \\
\hline Secondary Education & $117(50.6)$ & $142(48.5)$ & \\
\hline Higher Education & $18(7.8)$ & $29(9.9)$ & \\
\hline \multicolumn{4}{|l|}{ Marital status } \\
\hline Single & $83(35.9)$ & $91(31.1)$ & \multirow{4}{*}{$<0.001$} \\
\hline Married & $133(57.6)$ & $157(53.6)$ & \\
\hline Widow(er) & $1(0.4)$ & $22(7.5)$ & \\
\hline Divorced & $14(6.1)$ & $23(7.8)$ & \\
\hline \multicolumn{4}{|l|}{ Employment Status } \\
\hline Does not work & $120(51.9)$ & $232(79.1)$ & \multirow{2}{*}{$<0.001$} \\
\hline Active Worker & $111(48.1)$ & $61(20.9)$ & \\
\hline Time of Vigil (min/day) & 925.59 (123.05) & $902.32(116.76)$ & 0.028 \\
\hline Number of days & $6.43(0.66)$ & $6.36(0.67)$ & 0.205 \\
\hline SB (min/day) & $565.84(130.70)$ & 550.59 (119.87) & 0.166 \\
\hline MIPA (min/day) & $322.72(95.89)$ & $324.73(91.76)$ & 0.116 \\
\hline MOPA (min/day) & $37.82(14.18)$ & $27.28(19.20)$ & $<0.001$ \\
\hline VPA (min/day) & $1.10(0.18)$ & $0.31(0.14)$ & $<0.001$ \\
\hline MVPA (min/day) & $39.02(16.29)$ & $27.61(19.31)$ & $<0.001$ \\
\hline Steps/day & $14.978(5.721)$ & $13.443(4.610)$ & $<0.001$ \\
\hline Meet the recommendations for MVPA & $160(69.3)$ & $159(54.3)$ & $<0.001$ \\
\hline Bodyweight (kg) & $79.26(16.53)$ & $70.87(14.94)$ & $<0.001$ \\
\hline Height $(\mathrm{cm})$ & $171.67(7.00)$ & $159.28(7.07)$ & $<0.001$ \\
\hline $\mathrm{BMI}(\mathrm{Kg} / \mathrm{m} 2)$ & $26.91(5.43)$ & $27.95(5.63)$ & 0.003 \\
\hline \multicolumn{4}{|l|}{ BMI Classification } \\
\hline Underweight & $7(3.0)$ & $7(2.4)$ & \multirow{4}{*}{0.380} \\
\hline Normal weight & $81(35.1)$ & $84(28.7)$ & \\
\hline Excess weight & $85(36.8)$ & $108(36.9)$ & \\
\hline Obesity & $58(25.1)$ & $94(32.0)$ & \\
\hline Abdominal circumference $(\mathrm{cm})$ & $90.21(14.07)$ & $88.02(13.79)$ & 0.590 \\
\hline Bellow the threshold & $196(84.8)$ & $154(52.6)$ & $<0.001$ \\
\hline Neck circumference $(\mathrm{cm})$ & $36.88(4.18)$ & $32.99(4.23)$ & $<0.001$ \\
\hline Bellow the threshold & $171(74.0)$ & $210(71.7)$ & 0.548 \\
\hline
\end{tabular}

*Significance value of the Student t-test.

All measurements were calculated from the time of vigil.

SB: sedentary behavior; MIPA: mild physical activity; MOPA: moderate physical activity; VPA: vigorous physical activity; MVPA: moderate to vigorous physical activity; Min: minutes; BMI: Body Mass Index. 
Our results corroborate previous studies that showed a negative relationship between MVPA and body composition variables and risk factors, regardless of $\mathrm{SB}^{21}$. The study by Van Dyck et al. ${ }^{21}$ showed a curvilinear relationship of MVPA with the BMI and a probability of excess weight/obesity in adults. In men, MOPA and VPA seem to be worthy of behavioral targets associated with body composition variables. In the present study, VPA was the best predictor of body fat estimates. Similar to the previous findings, our results support the hypothesis that VPA has a potentially greater influence in the $\mathrm{AC}$ and $\mathrm{NC}$ than MOPA, even after adjusting for SB. Regarding public health, it is suggested that efforts should focus more

TABLE 2. ADJUSTED ANALYSES BETWEEN THE ACCELEROMETER VARIABLES AND THE ABDOMINAL CIRCUMFERENCE IN BRAZILIAN ADULTS

\begin{tabular}{|c|c|c|c|c|c|c|}
\hline \multirow{2}{*}{$\begin{array}{l}\text { Accelerometer } \\
\text { variables }\end{array}$} & \multicolumn{3}{|c|}{ Men } & \multicolumn{3}{|c|}{ Women } \\
\hline & $\beta$ coefficient & $95 \%$ IC & $p$-value & $\beta$ coefficient & $95 \%$ IC & $\mathrm{p}$-value \\
\hline $\mathrm{SB}(\min / \text { day })^{\mathbf{a}}$ & 0.002 & $-0.024,0.075$ & 0.353 & 0.002 & $0.011,0.038$ & 0.031 \\
\hline $\mathrm{SB}(\min / \text { day })^{\mathbf{b}}$ & 0.095 & $0.064,0.188$ & 0.257 & 0.003 & $0.002,0.006$ & 0.042 \\
\hline MIPA (min/day) ${ }^{\mathbf{a}}$ & -0.032 & $-0.021,0.014$ & 0.609 & 0.043 & $-0.011,0.026$ & 0.456 \\
\hline MIPA (min/day)c & -0.058 & $-0.027,0.010$ & 0.351 & -0.006 & $-0.020,0.018$ & 0.913 \\
\hline MOPA (min/day)a & -0.047 & $-0.087,-0.018$ & 0.032 & -0.002 & $-0.038,0.041$ & 0.951 \\
\hline MOPA (min/day)c & -0.005 & $-0.112,-0.020$ & 0.039 & -0.002 & $-0.048,0.055$ & 0.398 \\
\hline VPA (min/day) $)^{\mathbf{a}}$ & -0.114 & $-0.358,-0.104$ & $<0.001$ & -0.079 & $-0.379,0.371$ & 0.074 \\
\hline VPA (min/day)c & -0.126 & $-0.373,-0.107$ & $<0.001$ & -0.074 & $-0.425,0.299$ & 0.083 \\
\hline AFMV (min/day) & -0.055 & $-0.067,-0.045$ & 0.035 & -0.036 & $-0.074,0.058$ & 0.914 \\
\hline AFMV (min/day)c & -0.076 & $-0.094,-0.059$ & 0.021 & -0.047 & $-0.086,0.042$ & 0.377 \\
\hline Steps/daya & -0.002 & $-0.006,-0.001$ & $<0.001$ & -0.001 & $-0.001,0.002$ & 0.465 \\
\hline Steps/dayc & -0.005 & $-0.011-0.005$ & 0.035 & -0.002 & $-0.006,0.004$ & 0.062 \\
\hline
\end{tabular}

Note: All measurements were calculated from the time of vigil.

SB: sedentary behavior; MIPA: mild physical activity; MOPA: moderate physical activity; VPA: vigorous physical activity; MVPA: moderate to vigorous physical activity; min: minutes; $95 \%$ IC: $95 \%$ confidence intervals, $p<0.05$.

a Basic adjustment: region, age, ethnicity, level of education, marital status, and employment status.

b Full adjustment: region, age, ethnicity, level of education, marital status, employment status, and moderate to vigorous physical activity.

c Total adjustment: region, age, ethnicity, level of education, marital status, employment status, and sedentary behavior.

TABLE 3. ADJUSTED ANALYSES BETWEEN THE ACCELEROMETER VARIABLES AND THE NECK CIRCUMFERENCE IN BRAZILIAN ADULTS

\begin{tabular}{|c|c|c|c|c|c|c|}
\hline \multirow{2}{*}{$\begin{array}{l}\text { Accelerometer } \\
\text { variables }\end{array}$} & \multicolumn{3}{|c|}{ Men } & \multicolumn{3}{|c|}{ Women } \\
\hline & $\beta$ coefficient & $95 \%$ IC & p-value & $\beta$ coefficient & $95 \%$ IC & $\mathrm{p}$-value \\
\hline $\mathrm{SB}\left(\min /\right.$ day) ${ }^{\mathrm{a}}$ & -0.093 & $-0.006,0.003$ & 0.123 & -0.079 & $-0.007,0.001$ & 0.146 \\
\hline $\mathrm{SB}(\min / \text { day })^{b}$ & -0.117 & $-0.007,0.002$ & 0.062 & -0.095 & $-0.008,0.002$ & 0.134 \\
\hline MIPA (min/day) ${ }^{a}$ & 0.061 & $-0.003,0.021$ & 0.331 & -0.024 & $-0.002,0.008$ & 0.746 \\
\hline MIPA $(\mathrm{min} / \text { day })^{c}$ & 0.205 & $-0.005,0.317$ & 0.518 & -0.023 & $-0.007,0.004$ & 0.735 \\
\hline MOPA (min/day) ${ }^{a}$ & -0.082 & $-0.016,0.012$ & 0.280 & -0.018 & $-0.028,0.022$ & 0.163 \\
\hline MOPA $(\min / \text { day })^{c}$ & -0.083 & $-0.012,0.005$ & 0.174 & -0.048 & $-0.067,0.016$ & 0.101 \\
\hline VPA (min/day)a & -0.116 & $-0.260,-0.041$ & $<0.001$ & -0.109 & $-0.382,0.072$ & 0.054 \\
\hline VPA (min/day) & -0.113 & $-0.273,-0.032$ & 0.002 & -0.074 & $-0.422,0.008$ & 0.052 \\
\hline AFMV (min/day) & -0.057 & $-0.030,0.014$ & 0.131 & -0.280 & $-0.029,0.022$ & 0.290 \\
\hline AFMV (min/day) & -0.083 & $-0.031,0.008$ & 0.090 & -0.043 & $-0.036,0.017$ & 0.113 \\
\hline Steps/daya & -0.036 & $0.000,0.001$ & 0.581 & -0.046 & $0.000,0.001$ & 0.425 \\
\hline Steps/dayc & -0.073 & $0.000,0.001$ & 0.235 & -0.090 & $0.001,0.002$ & 0.143 \\
\hline
\end{tabular}

Note: All measurements were calculated from the time of vigil.

SB: sedentary behavior; MIPA: mild physical activity; MOPA: moderate physical activity; VPA: vigorous physical activity; MVPA: moderate to vigorous physical activity; min: minutes; $95 \%$ IC: $95 \%$ confidence intervals, $p<0.05$.

a Basic adjustment: region, age, ethnicity, level of education, marital status, and employment status.

b Full adjustment: region, age, ethnicity, level of education, marital status, employment status, and moderate to vigorous physical activity.

c Total adjustment: region, age, ethnicity, level of education, marital status, employment status, and sedentary behavior. 
on the promotion of MOPA than in VPA since MOPA can be achieved by walking and is more likely to be practiced by the population through appropriate promotion strategies.

MIPA was not significantly associated with any body composition variable, a finding consistent with most previous findings, showing no significant associations $^{22}$. It is, therefore, plausible that there is a intensity threshold in PA for body composition benefits. At least $250 \mathrm{~min} /$ week of MOPA ( $\geq 3$ metabolic units [METs]) are required if the primary goals are to reduce body mass and fat ${ }^{23}$. There is no recommendation regarding the time necessary of MIPA to achieve weight loss; however, the amount of MIPA necessary to improve body composition is possibly much greater than that of MVPA, given the reduced level of intensity ${ }^{22}$. In addition, evidence suggests that the total volume of PA is a key factor in achieving weight $\operatorname{loss}^{24}$. MIPA can help improve individuals' metabolic profile; however, there is a lack of evidence to support the effect of MIPA on the positive effects for CVD in adults 22 .

In our study, SB in women was significantly associated with the AC after adjustments for MVPA. This finding is consistent with a previous study ${ }^{25}$. Campbell et al. ${ }^{25}$ found that 1 hour/day in SB causes, on average, during a period of five years, changes in body weight and $\mathrm{AC}$ of $\leq 0.19 \mathrm{~kg}$, and $\leq 0.02 \mathrm{~mm}$, respectively. In addition, previous studies that reported a significant association between sedentary time and weight used mainly questionnaires that included questions about television time as a tool to measure sedentary time and did not report findings on general sedentary time.

On average, men spent more time in MVPA, MOPA, and VPA than women, which suggests that women had a higher prevalence of physical inactivity compared to men. Although the variability was high in each sex, women spent less time in MPA, VPA, and MVPA and had fewer steps/day. Increasing women's participation in MVPA is essential not only for health and quality of life, but also for the potential positive impacts on economic development in different geographical, cultural, and political contexts. We recommend, therefore, that Brazilian policymakers develop initiatives to promote PA among women.

The strengths of this study include the objective measurement of PA using techniques and approaches that are rare in countries like Brasil, unlike most of the previous studies that used questionnaires for indirect measurement of $\mathrm{PA}^{4}$. As far as we know, this is the first study that investigated the associations between accelerometry data with NC in Brasil. However, this study has several limitations: 1) Ebans had a cross-sectional design, preventing inferences on causality; 2) the MVPA estimates may not be representative of the total population of Brasil since participants were recruited based only on an urban residence, sex, age, and SEL; 3) only PA was examined in relation to the weight results; a more complete perspective could have been provided if measures related to diet, sleep, and more accurate measures of body fat had been included.

\section{CONCLUSION}

The present study provided evidence for significant associations between MOPA, VPA, MVPA, and steps/day with the AC. In this study, only VPA was associated with the NC. We found a strong association between MVPA (specifically VPA) and the AC, regardless of SB. VPA had a greater influence on the $\mathrm{AC}$ and NC than MOPA. In women, only SB was positively associated with the AC, regardless of MVPA. Our results are informative for the development of public policies and health programs intended to reduce the levels of physical inactivity and obesity, particularly in women.

\section{Acknowledgments}

We thank the Research Group and External Advisory Council of Ebans, the participants, and their families, all of whom made this study possible.

\section{Author's contribution}

G. L. M. Ferrari was responsible for the concept of the manuscript, conducted the statistical analyses, interpreted the data, and drafted the manuscript. E. R. Victo contributed to the drafting and critical revision of the manuscript. I. Kovalskys contributed in part to the concept of the study, provided statistical knowledge and critical review. A. V. Mello interpreted the data and drafted the discussion of the manuscript. A. N. Previdelli contributed to the data analysis and interpretation and provided critical revision of the manuscript. D. Solé provided critical revision of the manuscript. M. Fisberg contributed to the concept and design of the project and provided critical revision of the manuscript. All authors provided critical reviews, read, and approved the final manuscript. 


\section{RESUMO}

OBJETIVO: Investigar a associação do comportamento sedentário (CS) e da atividade física de moderada a vigorosa (AFMV), avaliados objetivamente, com variáveis de composição corporal em uma amostra de adultos brasileiros.

MÉTODOS: CS e AFMV foram monitorados por meio de acelerômetros no mínimo por cinco dias, em 524 participantes (231 homens; 18-65 anos). Cada período de epoch de um minuto foi classificado como sedentário, atividade física leve (AFL), moderada (AFM) ou vigorosa (AFV). As variáveis de composição corporal medidas foram: perímetro abdominal (PA) e circunferência do pescoço (CP).

RESULTADOS: Os homens acumularam significativamente ( $p<0,001)$ mais min/dia em AFM (37,82 versus 27,28$)$, AFV (1,10 versus 0,31), AFMV (39,02 versus 27,61), e passos/dia (14.978 versus 13.443) do que as mulheres. Nos homens, AFM, AFV, AFMV e passos/dia associaram-se $(p<0,05)$ negativamente com PA, independentemente do CS. Somente AFV associou-se significativamente $(\beta=-0,113$; $p=0,002)$ com CP. Já nas mulheres, apenas CS associou-se significativamente com o PA ( $\beta=0,003 ; p=0,031)$. Não houve associações significativas entre as intensidades de atividade física com a composição corporal nas mulheres.

CONCLUSÕES: Nossos achados sobre a associação desigual da atividade física com composição corporal entre os sexos aumentam a base de evidências e podem ajudar a informar futuras estratégias de intervenção no Brasil.

PALAVRAS-CHAVE: Acelerometria. Obesidade. Antropometria.

\section{REFERENCES}

1. Kanejima Y, Kitamura M, Izawa KP. Self-monitoring to increase physical activity in patients with cardiovascular disease: a systematic review and meta-analysis. Aging Clin Exp Res. 2019;31(2):163-73.

2. Biddle SIH, Garcia Bengoechea E, Pedisic Z, Bennie |, Vergeer I, Wiesner G. Screen time, other sedentary behaviours, and obesity risk in adults: a review of reviews. Curr Obes Rep. 2017;6(2):134-47.

3. Instituto Brasileiro de Geografia e Estatística (IBGE). Pesquisa de orçamentos familiares (POF). 2008-2009. [cited 2019 Maio 25]. Available from: http://www.ibge.gov.br/home/estatistica/populacao/condicaodevida/ pof/2008_2009_aquisicao/pof20082009_aquisicao.pdf

4. Mielke GI, Hallal PC, Rodrigues GBA, Szwarcwald CL, Santos FV, Malta DC Physical activity and television viewing among Brazilian adults: National Health Survey 2013. Epidemiol Serv Saúde. 2015;24(2):277-86.

5. World Health Organization. WHO guidelines approved by the Guidelines Review Committee. Global recommendations on physical activity for health. Geneva: World Health Organization; 2010.

6. Ferrari GL, Oliveira LC, Araujo TL, Matsudo V, Barreira TV, Tudor-Locke C, et al. Moderate-to-vigorous physical activity and sedentary behavior: independent associations with body composition variables in Brazilian children. Pediatr Exerc Sci. 2015;27(3):380-9.

7. Fisberg M, Kovalskys I, Gómez G, Rigotti A, Cortés LY, Herrera-Cuenca M, et al; ELANS Study Group. Latin American Study of Nutrition and Health (ELANS): rationale and study design. BMC Public Health. 2016;16:93.

8. Fisberg M, Kovalskys I, Previdelli AN, Zimberg IZ, Del'Arco APWT, Ferrari GLM. Brazilian Study of Nutrition and Health (EBANS) - Brazilian data of ELANS: methodological opportunities and challenges. Rev Assoc Med Bras. 2019;65(5):669-77.

9. Colley R, Connor Gorber S, Tremblay MS. Quality control and data reduction procedures for accelerometry-derived measures of physical activity. Health Rep. 2010;21(1):63-9.

10. Trost SG, Loprinzi PD, Moore R, Pfeiffer KA. Comparison of accelerometer cut points for predicting activity intensity in youth. Med Sci Sports Exerc. 2011;43(7):1360-8.

11. Salvo D, Sarmiento OL, Reis RS, Hino AAF, Bolivar MA, Lemoine PD, et al. Where Latin Americans are physically active, and why does it matter? Findings from the IPEN-adult study in Bogota, Colombia; Cuernavaca, Mexico; and Curitiba, Brasil. Prev Med. 2017;103S:S27-S33.

12. Freedson PS, Melanson E, Sirard J. Calibration of the computer science and applications, Inc. accelerometer. Med Sci Sports Exerc. 1998;30(5):777-81.
13. Lohman T. Anthropometric standardization reference manual. Champaign: Human Kinetics; 1988.

14. World Health Organization (WHO). Physical status: the use and interpretation of anthropometry. Geneva: World Health Organization; 1995.

15. World Health Organization. Obesity: preventing and managing the global epidemic. WHO Technical Report Series, 894. Geneva: World Health Organization; 1998.

16. World Health Organization. Obesity: preventing and managing the global epidemic. Report of a WHO consultation. World Health Organ Tech Rep Ser. 2000;894:i-xii, 1-253.

17. National Institutes of Health. Clinical guidelines on the identification, evaluation, and treatment of overweight and obesity in adults: the evidence report. Obes Res. 1998;6(Suppl 2):51S-209S.

18. Ben-Noun L, Sohar E, Laor A. Neck circumference as a simple screening measure for identifying overweight and obese patients. Obes Res. 2001;9(8):470-7.

19. Cornier MA, Després JP, Davis N, Grossniklaus DA, Klein S, Lamarche B, et al. Assessing adiposity: a scientific statement from the American Heart Association. Circulation. 2011;124(18):1996-2019.

20. Onat A, Hergenç G, Yüksel H, Can G, Ayhan E, Kaya Z, et al. Neck circumference as a measure of central obesity: associations with metabolic syndrome and obstructive sleep apnea syndrome beyond waist circumference. Clin Nutr. 2009;28(1):46-51.

21. Van Dyck D, Cerin E, De Bourdeaudhuij I, Hinckson E, Reis RS, Davey $R$, et al. International study of objectively measured physical activity and sedentary time with body mass index and obesity: IPEN adult study. Int J Obes (Lond). 2015;39(2):199-207.

22. Batacan RB |r, Duncan M|, Dalbo V|, Tucker PS, Fenning AS. Effects of light intensity activity on CVD risk factors: a systematic review of intervention studies. Biomed Res Int. 2015;2015:596367.

23. Proper and improper weight loss programs. Med Sci Sports Exerc 1983;15(1):ix-xiii.

24. Kohl H, Murray T. Foundations of physical activity and public health. Champaign: Human Kinetics; 2012.

25. Campbell SDI, Brosnan BJ, Chu AKY, Skeaff CM, Rehrer NJ, Perry TL, et al. Sedentary behavior and body weight and composition in adults: a systematic review and meta-analysis of prospective studies. Sports Med. 2018;48(3):585-95 